\title{
What is Scientific Progress? Lessons from Scientific Practice
}

\author{
Moti Mizrahi
}

St. John's University

\begin{abstract}
In a recent debate about the nature of scientific progress, Alexander Bird and Darrell Rowbottom have argued for two competing accounts of progress. According to Bird, scientific progress consists in the accumulation of scientific knowledge. Rowbottom, on the other hand, thinks that truth alone is necessary for progress. Both use thought experiments and appeal to intuitions in support of their views, and it seems fair to say that the debate has reached an impasse. In an attempt to avoid this stalemate, I propose to abandon appeals to intuitions and turn to scientific practice instead. I propose to examine the institution of the Nobel Prize, where scientists award their peers for what they consider to be important contributions to science, in order to shed new light on the question of scientific progress. I discuss two case studies that illustrate the way in which scientists make judgments about progress. As far as scientists are concerned, progress is made when scientific discoveries contribute to the increase of scientific knowledge of the following sorts: empirical, theoretical, practical, and methodological. I then propose that we should articulate an account of scientific progress that does justice to the way in which scientists evaluate progress. I discuss one way of doing so, namely, by abandoning the distinction between 'knowing that' and 'knowing how' and granting that know-how counts as scientific knowledge.
\end{abstract}

Keywords: aim of science; Alexander Bird; Darrell Rowbottom; scientific knowledge; scientific practice; scientific progress; truth

\section{Introduction}

According to Chang (2007, p. 1), "Scientific progress remains one of the most significant issues in the philosophy of science today." This is partly because it seems rather odd to deny that science is making progress, but it is difficult to articulate in what sense exactly science is making progress. Recently, Bird (2007) has argued for an account of progress that has a rich tradition. According to Bird (2007, p. 64):

Science (or some particular scientific field or theory) makes progress precisely when it shows the accumulation of scientific knowledge; an episode in science is progressive when at the end of the episode there is more knowledge than at the beginning.

As Bird admits, this conception of scientific progress is not new. The idea of the growth of knowledge looms large in the history of science, at least from the early modern period. It may be traced back to Francis Bacon, whose Instauratio magna (1620) frontispiece declares: "Multi pertransibunt et augebitur scientia."1 Sarton (1927, I, pp. 3-4) expressed a similar idea as follows: "The acquisition and systematization of positive knowledge is the only human activity which is truly cumulative and progressive." However, as Bird notes, it seems that philosophers

\footnotetext{
${ }^{1}$ The Hebrew passage in Daniel 12:4 reads "many shall wander, and knowledge shall increase."
} 
of science have ignored this conception of scientific progress, at least since the publication of Kuhn's The Structure of Scientific Revolutions. Similarly, Kitcher (2002, p. 385) observes that:

Almost everybody seems to agree that the sciences constitute the richest and most extensive body of human knowledge, and scientists routinely talk of "what we now know." Within the philosophy of science, however, there is little explicit discussion of scientific knowledge.

Bird (2008, p. 279) distinguishes between epistemic and semantic accounts of scientific progress as follows:

(E) An episode constitutes scientific progress precisely when it shows the accumulation of scientific knowledge.

(S) An episode constitutes scientific progress precisely when it either (a) shows the accumulation of true scientific belief, or (b) shows increasing approximation to true scientific belief. $^{2}$

By considering several thought experiments, Bird (2007, p. 65) argues that "our intuitions about whether there is progress show that progress matches changes in knowledge, but not changes in truth," and that (S) "has no theoretical advantages over" (E).

Against (S), Bird (2007) propounds the following arguments, which show that cases of increase in truth, without justification, are not cases of progress. In other words, increase in truth alone is not sufficient for progress.

1. A sequence of lucky guesses or irrational beliefs with increasing verisimilitude will be progressive on (S). Intuitively, however, and on (E), it is not.

2. Suppose a scientific community accidentally forms approximately true beliefs based on an irrational method. One scientist realizes that the method is irrational, and the scientific community rejects its previously held beliefs. On (S), this community was making progress, and then regressed (after it was discovered that the method is irrational). Intuitively, however, and on $(\mathrm{E})$, this community made progress after the discovery that the method is irrational.

3. Suppose that we were to discover that there are entities answering to René Blondlot's description of N-rays. On (S), this would be a case of progress because the belief is true. But Blondlot's reasons for positing N-rays were entirely spurious and irrational, and hence not knowledge. (Apparently, his belief was largely the result of self-deception.)

4. On (S), it would have been more progressive to have accepted Alfred Wegener's theory of continental drift at the time. On (E), however, it was rational to reject it, or at least suspend judgment, at the time because Wegener didn't have sufficiently compelling evidence in its support.

According to Bird, these arguments show that increase in truth is not sufficient for progress. As Bird (2007, p. 65) writes: (S) "yields a verdict about progress in certain kinds of case [i.e., cases

\footnotetext{
${ }^{2}$ Proponents of (S) include Popper (1979) and Niiniluoto (1987).
} 
of beliefs with insufficient epistemic support] that is at odds with our intuitions." These intuitions, according to Bird (2007, p. 65), "imply that epistemic characteristics are essential to progress."

For Bird, then, there is progress in science whenever there is an increase in scientific knowledge. It is important to note that Bird does not take knowledge to be justified true belief. Rather, he thinks that his arguments support Williamson's view that knowledge is a foundational concept in epistemology and that it does not have an analysis. ${ }^{3}$ According to Bird (2007, p. 85):

A major feature of [Williamson's] conception [of knowledge] is the view that belief aims at knowledge. It is as if we only have the concept of belief in order to describe the mental state we are in when we have attempted to know but have failed. While Williamson does not argue for this claim directly, the motivating role it plays in his overall conception means that the success of his arguments would strongly support that view. From this perspective, the arguments for the knowledge view of scientific progress can be seen as a contribution to the same project.

It is also important to note that to say that knowledge is an unanalyzable primitive does not amount to denying that knowledge entails truth. As Williamson (2000, p. 3) writes:

a necessary but insufficient condition need not be a conjunct of a non-circular necessary and sufficient condition. Although being coloured is a necessary but insufficient condition for being red, we cannot state a necessary and sufficient condition for being red by conjoining being coloured with other properties specified without reference to red. Neither the equation ' $R e d=$ coloured $+X$ ' nor the equation 'Knowledge $=$ true belief + $\mathrm{X}^{\prime}$ need have a non-circular solution.

In other words, that $p$ be true could be a necessary but insufficient condition for ' $S$ knows that $p$ ' without it being the case that there is an analysis of ' $S$ knows that $p$ ' in terms of ' $p$ is true' plus some additional conditions.

So, according to Bird, if belief aims at knowledge, then scientific belief aims at scientific knowledge. Progress in science would then be attaining knowledge rather than merely truth. This is another advantage of (E) over (S), according to Bird (2007, p. 83), not only because aiming at truth, unlike aiming at knowledge, does not entail that one desires to avoid falsehood as well, but also because knowledge is harder to achieve, and thus more stable than true belief. ${ }^{4}$

Contrary to Bird, Rowbottom argues against (E) and in support of (S). Rowbottom doesn't share Bird's intuitions about putative cases of progress. In his recent reply to Bird, Rowbottom (2010, pp. 242) provides the following thought experiment:

Consider two planets; the inhabitants of the first have no justified scientific beliefs (although they have many true ones), whereas the inhabitants of the second have many justified scientific beliefs and considerable scientific knowledge. But the civilisations on

\footnotetext{
${ }^{3}$ See Williamson (1997) and (2000).

${ }^{4}$ Henceforth, I will take knowledge to be an unanalyzable primitive in the same way that Williamson and Bird do.
} 
each of these planets appear, on the surface, to be equally as advanced. Each has developed similar technology, has similar societies and institutions, uses similar scientific theories, and so forth. Roughly, we'd say they were at the same stage of technological development as we were at the turn of the twentieth century. Now add that the people on each of the planets began in similarly primitive circumstances and proceeded without any outside interference. In short, neither group had an initial theoretical or technological advantage over the other, or acquired one from an external source.

For Rowbottom, this thought experiment refutes $(\mathrm{E})$, since his intuition is that the people on each planet have made some scientific progress (which need not be equal). This shows, according to Rowbottom, that scientific progress is possible without justification, and since knowledge entails justification, scientific progress does not consist in the accumulation of knowledge.

Both Bird and Rowbottom, then, offer thought experiments and appeal to intuitions in support of their views, and it seems fair to say that the debate has reached an impasse. In an attempt to avoid this stalemate, I propose to study actual scientific practices rather than appeal to intuitions. In particular, I propose to examine the institution of the Nobel Prize in an attempt to shed new light on the question of scientific progress. I think that examining episodes from the history of the Nobel Prize might be illuminating as far as the question of scientific progress is concerned, since the Nobel Prize is a setting where scientists award their peers for what they consider to be important contributions to science.

In what follows, then, I will examine (S) and (E) from a naturalistic perspective. Taking a naturalistic stance means articulating philosophical accounts about science that are historically informed. This idea is expressed by Imre Lakatos' (1970, p. 91) paraphrase of a Kantian thesis: "Philosophy of science without history of science is empty; history of science without philosophy of science is blind." More than simply being historically informed, however, naturalistic accounts of science must also do justice to the actual practices of scientists. As Bird (2008, p. 73) puts it:

even if one thinks of history of science as descriptive and philosophy of science as normative, the former can be relevant to the latter in that, given certain assumptions about science in fact satisfying the norms (e.g., science is largely rational), it had better be that the historian's description meshes with the philosopher's prescription.

What this means, at a minimum, is that if we want to answer questions about the nature of science, such as "What is scientific progress?", then we have to look at the history of science and the actual practices of scientists. As Leplin (1997, p. 99) writes:

increasingly in epistemology, and especially in the philosophy of science, theories have been redirected toward methods of inquiry that can be empirically assessed for their utility in advancing cognitive goals without prejudice as to whether they are believed by practitioners to advance these goals, or whether they fit popular preconceptions as to what knowledge is or how it is acquired. This development abandons philosophy's traditional claim to a priori status in favor of an essential continuity of philosophy with empirical science. 
By taking a naturalistic stance, then, we abandon first philosophy; philosophy thus becomes continuous with science. Taking a naturalistic stance means that an account of scientific progress is itself a scientific hypothesis. As Leplin (1997, p. 102) puts it:

The view that philosophical theories of science are to be judged against scientific practice, much as science is judged against natural phenomena, is a form of naturalism in epistemology. [...] The idea is that epistemological theories actually are scientific theories, albeit of a highly abstract and general kind. Just as scientific theories are responsible to the workings of the natural world, a theory about the assessment of scientific theories is a theory about evaluative practice in science, and is responsible to this practice. According to naturalism, there is nothing else for it to be about, for there is no source of facts about how theories ought to be evaluated apart from scientific experience.

Accordingly, just as scientific theories are responsible to the workings of nature, and are evaluated relative to natural phenomena, a theory about scientific progress is a theory about an evaluative practice in science, and is responsible to this practice. To paraphrase Quine, I wish to find out how (S) and (E) fare when they face the tribunal of scientific practice. To do so, I will discuss two case studies and then see how each account of progress can accommodate these case studies.

\section{Landsteiner's Discovery of Blood Groups}

Karl Landsteiner (1868-1943) was awarded the Nobel Prize in Physiology or Medicine in 1930 for his discovery of human blood groups. The Presentation Speech for the 1930 Nobel Prize in Physiology or Medicine was delivered by G. Hedrén, chairman of the Nobel committee for physiology or medicine of the Karolinska Institutet. In his speech, Hedrén (1930) recounted the reasons why Landsteiner's discovery advanced the biomedical sciences:

Landsteiner's discovery of the blood groups [...] has opened up new avenues of research in several branches of science and has brought with it important advances in the purely practical field. However, it is only recently that the scientific importance of Landsteiner's discovery has been fully realized (my emphasis). ${ }^{5}$

According to Hedrén, Landsteiner's discovery yielded practical applications in medicine as well as new methods that proved useful in other fields. For example, the purification techniques he used in his own research, i.e., techniques of purifying antibodies by dissociating them from antigens, were later used (and are still used today for some applications) in immunology (Landsteiner and Miller 1925). In addition (Hedrén 1930):

In the field of genetics the discovery of the blood groups has also proved to be of importance from the point of view of methodology in the study of the hereditary transmission of other characteristics. [It] also prompted research on the questionimportant for the study of constitution - whether other body cells in addition to

\footnotetext{
${ }^{5}$ Available at <http://nobelprize.org/nobel_prizes/medicine/laureates/1930/press.html>.
} 
erythrocytes, and in particular the germinal cells, can be differentiated according to specific groups (my emphasis).

So, according to Hedrén, in addition to the medical applications that his discovery brought about, Landsteiner was awarded the Nobel Prize because his discovery also opened up new avenues of research in several branches of science and it proved to be important methodologically in the study of the hereditary transmission of other characteristics.

In his Nobel Lecture, Landsteiner explained how new methods led to new discoveries. As Landsteiner (1930) said, "it was not the usual chemical methods but the use of serological reagents which led to an important general result in protein chemistry, namely to the knowledge that the proteins in individual animal and plant species differ and are characteristic of each species." 6 This general result helped Landsteiner in his experiments concerning the phenomena of agglutination, i.e., when mixing blood from two individuals can lead to blood clumping and the clumped red cells can crack and cause toxic reactions. Before Landsteiner, it was commonly believed that agglutination is a pathology. But Landsteiner showed that it was due to the unique nature of the individual's blood. Blood clumping is an immunological reaction that occurs when the receiver of a blood transfusion has antibodies against the donor blood cells. He grouped blood types into three groups, which he designated as $\mathrm{A}, \mathrm{B}$, and $\mathrm{C}$ (which later became $\mathrm{O}$ and the AB blood group was subsequently added by others). Thanks to Landsteiner's work, the first successful blood transfusion took place in Mt. Sinai Hospital in New York in 1907.

\section{Pavlov's Work on the Physiology of Digestion}

In 1904, Ivan Petrovich Pavlov (1849-1936) received the Nobel Prize in Physiology or Medicine "in recognition of his work on the physiology of digestion, through which knowledge on vital aspects of the subject has been transformed and enlarged." K. A. H. Mörner (1904), who delivered the Presentation Speech, opened his speech as follows:

The medical sciences are mutually interdependent. Progress in one field is often closely associated with development in others. The rise in one branch of science can often have its origin in a recently made analysis within another sphere, and yet it may appear at the first glance that the former is of outstanding importance while the latter is apparently of second value. It is not always such progress, as immediately are useful and of benefit, which should be considered as especially important; this character can also be attributed to those which are themselves less spectacular but form the basis for the others which are then only a further development of it. ${ }^{7}$

According to Mörner, then, scientific discoveries are not sudden acts of creativity by isolated geniuses whose task is then simply to convince the scientific community that they have stumbled upon the truth (Zuckerman 1996). Also, discoveries that initially appear less spectacular may turn out to have great value. But what is the aim of science relative to which we make judgments about progress? According to Mörner (1904):

\footnotetext{
${ }_{7}^{6}$ Available at <http://nobelprize.org/nobel_prizes/medicine/laureates/1930/landsteiner-lecture.pdf >

${ }^{7}$ Available at <http://nobelprize.org/nobel_prizes/medicine/laureates/1904/press.html>.
} 
The aim of science is the acquisition of knowledge, the value of which should not be measured by the ease with which it can be brought immediately into practical usefulness (my emphasis).

So the aim of science, according to Mörner, is the attainment of knowledge. Assessments of progress, then, must be made relative to this aim. As Mörner (1904) said:

The importance of the activities of these men [i.e., Vesalius and Harvey] for the whole of Medical Science must be estimated from the contributions they gave to the advancement of knowledge (my emphasis).

How was this aim achieved in the case of Pavlov? According to Mörner (1904):

In the early days opinions on the course of digestion were speculations as to what was termed as 'cooking' or 'grinding' in the stomach, etc. So long as the digestive processes could not be observed or investigated directly in the stomach no real knowledge could be obtained (my emphasis).

How did Pavlov help improve upon the state of knowledge in the field? According to Mörner (1904):

An accident turned physiological research in this field in a direction which has later become very important. In the 1820's a young man sustained a gunshot wound in the stomach and developed a gastric fistula which to some extent permitted the gastric processes to be studied. Observations were carried out on this man by the American physician W. Beaumont. This accidental path of investigation, allowing actual observation of processes taking place in the digestive tract, was later followed by many workers using animals. Technique is an important factor in such experiments and has been perfected in a masterly way by Pavlov, whose animals remain in good health, without any injury to the function of their digestive tract, permitting observation and systematic investigation over an almost unlimited period.

According to Mörner, then, Pavlov made contributions not only in terms of factual knowledge about digestion but also in terms of methods and techniques of investigation. As Mörner (1904) put it:

These methods for the study of the physiology of digestion established by Pavlov have been taken up by various physiological institutions, but above all much important work was performed in his own laboratory. From this has followed far-reaching transformation of our knowledge in this field which has also been enriched by new fundamental facts (my emphasis).

Why Pavlov was awarded the Nobel Prize in Physiology or Medicine? According to Mörner (1904): 
Before Pavlov, knowledge in this field was in many respects very imperfect. Pavlov has corrected earlier erroneous opinions which were held even with regard to the main points within this part of physiology. He has further enriched it with significant data (my emphasis).

Accordingly, in addition to contributions in terms of new methods and techniques of investigation (one, in particular, became known as the "chronic experiment," involving intact animals), Pavlov corrected erroneous beliefs and added new factual knowledge about the physiology of digestion. What additional knowledge did Pavlov add to the field? According to Mörner (1904):

Before Pavlov's work it was the general opinion that the gastric secretion was not influenced via the nerves connecting the stomach and the central nervous system. This conception has, however, been shown to be incorrect. Pavlov has demonstrated that the vagus nerve linking the brain with various thoracic and abdominal organs contains fibers which during their activity stimulate gastric secretion and others which have an exactly opposite effect. In this way the secretion of gastric juice is controlled by the central nervous system and can be influenced from different parts of the body.

So Pavlov exposed erroneous opinions and corrected them. Furthermore (Mörner 1904):

Pavlov has enriched our knowledge of the significance and functions of this important nerve in other respects also. The vagus nerve paths are not, it appears, the only simulators of gastric secretion. Pavlov has shown that it may also be influenced through the sympathetic nervous system (my emphasis).

Pavlov also added to the already existing, yet incomplete, knowledge about the vagus nerve. In addition (Mörner 1904):

Pavlov has also demonstrated another aspect of the functional association between the gastric mucous and the nervous system, in the specific excitability of the mucous membrane itself. Before the work of Pavlov it was supposed that it could be brought into activity by almost anything within the stomach. Purely mechanical contact was considered to have this effect. Pavlov demonstrated, however, that this generally accepted view was incorrect. The reverse is true, the gastric mucous membrane having a sharply differentiated excitability for special substances with which it comes into contact. Thus there are relationships reminiscent of the specific excitability of the sense organs (my emphasis).

In addition to showing that previously held beliefs were false and correcting them, Pavlov also contributed to physiology by adding new knowledge. According to Mörner (1904):

It is now known, thanks to Pavlov, that a similar specific excitability is present in the mucous membrane lining the digestive tract, even though the subject is not conscious of it, and it acts by influencing the processes of secretion and of motility of the canal (my emphasis). 
Furthermore (Mörner 1904):

As another aspect of this specific sensitivity of the gastric mucous membrane one must consider the remarkable fact, demonstrated by Pavlov, that the amount of gastric secretion and its digestive strength show certain typical variations dependent upon the quality of the food taken.

This is just a sample of the contributions to the knowledge of the physiology of gastric secretion and other aspects of the physiology of the stomach made by Pavlov (Mörner 1904). Being familiar with the full extent of his contributions, however, Pavlov's colleagues could judge that (Mörner 1904):

Through Pavlov's work we have obtained a much more extensive and clearer insight than our previous knowledge could give us. We have now a fairly comprehensive view of the influence which the activity of one portion of the digestive apparatus can exert on another; in other words how the wheels of the digestive mechanism fit together for the efficient use and advantage of the body (my emphasis).

Accordingly, Pavlov's work on digestion was deemed a major contribution to the progress of physiology by his colleagues. In Pavlov's case, the reasons include revising imperfect knowledge, correcting erroneous opinions, and devising new methods and techniques for the study of the physiology of digestion. These epistemic reasons, in terms of the rejection of false beliefs, correction of erroneous opinions, and addition of new knowledge, are the grounds for the judgment that "Pavlov's work on digestion has been found to be of great importance for the study of disease, and undoubtedly the progress made in physiological knowledge in this case as well as in others will lead to a transformation of the concepts of diseases and their treatments" (Mörner 1904). For these reasons, Pavlov was awarded the 1904 Nobel Prize in Physiology or Medicine.

In his Nobel Lecture on the physiology of digestion, Pavlov (1904) identified the following aim for physiology:

Precise knowledge of what happens to the food entering the organism must be the subject of ideal physiology, the physiology of the future. Present-day physiology can but engage in the continuous accumulation of material for the achievement of this distant aim (my emphasis). ${ }^{8}$

After he surveyed the state of knowledge in the field before his contributions and explained how his contributions added to or corrected existing knowledge, Pavlov judged that the science of physiology "is making huge progress every day" (Pavlov 1904).

\section{Lesson from Scientific Practice}

\footnotetext{
${ }^{8}$ Available at <http://nobelprize.org/nobel_prizes/medicine/laureates/1904/pavlov-lecture.html>.
} 
Taking (S) and (E) to be scientific hypotheses, as they should be understood from a naturalistic perspective, they yield specific predictions. According to $(\mathrm{S})$, truth is the aim of science. So, assuming that scientists are aware of the goal they are pursuing, ${ }^{9}$ we would expect scientists to talk about the aim of science in terms of truth. As we have seen, however, this is not what we find. The case studies discussed above show that scientists talk about the aim of science in terms of knowledge rather than merely truth. This way of talking about the aim of science is further confirmed by what scientists say even beyond the setting of the Nobel Prize, which is what we would expect if (E) were true, since, according to (E), knowledge is the aim of science. Here are two examples:

It is not in the nature of things for any one man to make a sudden violent discovery; science goes step by step, and every man depends on the work of his predecessors. When you hear of a sudden unexpected discovery - a bolt from the blue, as it were-you can always be sure that it has grown up by the influence of one man on another, and it is this mutual influence which makes the enormous possibility of scientific advance. Scientists are not dependent on the ideas of a single man, but on the combined wisdom of thousands of men, all thinking of the same problem, and each doing his little bit to add to the great structure of knowledge which is gradually being erected (Rutherford 1947, p. 178, my emphasis).

[Science] is the accumulation of humanity's organized, objective knowledge, the first medium devised to unite people everywhere in common understanding (Wilson 1999, p. 269, my emphasis).

From a naturalistic standpoint, then, one could make the following argument against $(\mathrm{S})$ :

1. If (S) is true, then scientists would talk about that aim in terms of truth. [Assuming that scientists are thoughtful enough to reflect on the aim of their profession.]

2. It is not the case that scientists talk about the aim of science in terms of truth. [As the aforementioned case studies show.]

3. (Therefore) $(\mathrm{S})$ is (probably) not true.

Like any disconfirmation argument, this argument does not amount to a refutation of (S), even though it is formally valid. Proponents of (S) could always reject the assumption that scientists are cognizant of the aim of science, but then they would have to say why scientists, unlike other professionals, fail to understand the aim of their profession (see footnote 9).

On the other hand, one could make the following argument in support of (E):

\footnotetext{
${ }^{9}$ One might think that this is an unwarranted assumption. However, I think that there is no more reason to think that scientists are oblivious to the goals of their enterprise than footballers are oblivious to the goals of football, plumbers are oblivious to the goals of plumbing, or teachers are oblivious to the goals of teaching. The burden of proof, then, is on those who think that scientists are different in that respect to show that scientists are indeed different from footballers, plumbers, teachers, etc., in some relevant way that bears on their ability to make judgments about the goals of science. Furthermore, if the goal is to understand scientific progress, then, from a naturalistic standpoint, it makes more sense to test philosophical accounts of progress against the judgments of scientists than against the intuitions of philosophers.
} 
1. If (E) is true, then scientists would talk about that aim in terms of knowledge. [Assuming that scientists are thoughtful enough to reflect on the aim of their profession.]

2. Scientists talk about the aim of science in terms of knowledge. [As the aforementioned case studies show.]

3. (Therefore) (E) is (probably) true.

Like any confirmation argument, this argument does not amount to a demonstration that (E) is true, since it is formally invalid. Again, proponents of (S) could always reject the assumption that scientists are cognizant of the aim of science. But it does seem to provide some evidence in support of $(E)$, since $(E)$ can readily explain why scientists talk about knowledge as the aim of science, whereas $(\mathrm{S})$ does not seem to be able to account for that.

Furthermore, if $(\mathrm{S})$ were true, we would expect scientists to evaluate progress in science relative to semantic criteria, i.e., criteria that have to do with truth alone, assuming that scientists can make judgments about what counts as progress in science. ${ }^{10}$ As we have seen, however, this is not what we find. The case studies discussed above show that scientists evaluate progress in science relative to epistemic criteria, i.e., criteria that have to do with knowledge, which is what we would expect if (E) were true. More explicitly, from the aforementioned case studies, and others like them, we can discern the following pattern, which seems to be the way scientists make judgments about progress:

(PA1) Survey the body of knowledge $B$ in field $F$ at time $t$ prior to discovery $D$.

(PA2) Estimate what was known $(B)$ in $F$ at $t$.

(PA3) Identify a lacuna, imprecision or error in $B$ at $t$.

(PA4) Spell out how $D$ improved on $B$ by adding new knowledge, correcting imprecision or exposing errors and correcting them.

In Landsteiner's case, a survey of the body of knowledge before his work reveals (a) a lacuna in terms of knowledge about the function of different proteins in different species, and (b) erroneous beliefs about the phenomenon of agglutination. Landsteiner corrected these erroneous beliefs and added new factual knowledge about the nature and function of blood clumping.

In Pavlov's case, a survey of the body of knowledge on the physiology of digestion before Pavlov's work reveals (a) a lacuna in terms of knowledge about the function of the digestive canal, the salivary glands, the intestinal canal, gallbladder, and the role of the nervous system, and (b) erroneous beliefs about the function of the vagus nerve and gastric secretion and how the gastric mucous membrane is excited by mechanical contact. Pavlov corrected these erroneous beliefs and added new factual knowledge about the stimulation of gastric secretion by the vagus nerve and the sympathetic nervous system, the differential excitability of the gastric mucous membrane relative to various substances and a similar one in the case of the mucous membrane lining the digestive tract. For example, as a result of Pavlov's work, it is known that

\footnotetext{
${ }^{10}$ Another kind of accounts of progress, which I will not discuss in this paper, is what Bird calls "FunctionalInternalist" (FI) accounts of progress. According to (FI), "An episode shows scientific progress precisely when it achieves a specific goal of science, where that goal is such that its achievement can be determined by scientists at that time (e.g., solving scientific puzzles)" (Bird 2008, p. 279). On (FI), progress can be assessed internally by scientists themselves. Proponents of (FI) include Kuhn and Laudan.
} 
"stimulation of gastric secretion of acid and pepsin and stimulation of pancreatic secretion of digestive enzymes starts with the anticipation of the ingestion of a desirable meal and is mediated by input to the stomach and pancreas from efferent nerves of the vagus" (Wood 2004, p. 327).

In addition to showing that scientists make judgments about progress that are based on epistemic criteria, rather than criteria that have to do with truth alone, the aforementioned case studies also show that scientists take progress to consist in the accumulation of knowledge of the following sorts:

(EK) Empirical Knowledge: Empirical knowledge usually comes in the form of experimental and observational results.

(TK) Theoretical Knowledge: Theoretical knowledge usually comes in the form of well-confirmed hypotheses.

(PK) Practical Knowledge: Practical knowledge usually comes in the form of both immediate and long-term practical applications.

(MK) Methodological Knowledge: Methodological knowledge usually comes in the form of methods and techniques of learning about domains in nature.

In the case of Landsteiner's discovery of blood groups, we have accumulation of knowledge of the following sorts:

(EK) knowing that mixing blood from two human beings can lead to blood clumping or agglutination; knowing that the clumped red cells can crack and cause toxic reactions.

(TK) knowing that blood clumping is an immunological reaction that occurs when the recipient of a blood transfusion has antibodies against that donor blood cells; knowing that there are distinct blood groups that can be classified according to the $\mathrm{ABO}$ and $\mathrm{Rh}$ systems (among others).

(PK) knowing how to determine blood groups and type human blood; knowing how to carry out safe blood transfusions; knowing how to type dried blood stains in the investigation of crimes where blood stains are left at the scene (though, nowadays, there are other methods of typing, in addition to forensic serology, involving other body fluids and DNA).

(MK) knowing how to purify antibodies to study immunological responses and allergic reactions (since antigens as diverse as bacteria, pollen grains, and foreign red blood cells trigger the synthesis of antibodies in the lymphoid tissue).

As we have seen, Landsteiner was deemed worthy of the Nobel Prize because his discovery led to an increase not only in theoretical knowledge but also in practical and methodological knowledge. In other words, scientists judged that medical science advanced, due to Landsteiner's work, not only because of the theoretical knowledge of blood types, but also because of the practical knowledge of blood transfusions and forensic serology, and the methodological knowledge of antibody purification. 
In Pavlov's case, his work on the physiology of digestion was judged to have been progressive in terms of theoretical and empirical knowledge:

(EK) knowing that stimulation of gastric secretion of acid and pepsin and stimulation of pancreatic secretion of digestive enzymes starts with the anticipation of the ingestion of desirable food.

(TK) knowing that stimulation of pancreatic secretion of digestive enzymes is mediated by input to the stomach and pancreas from efferent nerves (i.e., nerves that carry impulses away from the brain or spinal cord) of the vagus; knowing that the stimulation of secretion induced by connecting environmental stimuli with appearance of tasty food is a conditioned reflex.

In addition, and equally important, Pavlov's work was judged to have been progressive in terms of practical and methodological knowledge as well:

(PK) knowing how to treat peptic and duodenal ulcer disease with selective vagotomy (in selective vagotomy, the branches of the vagus nerve to the gall bladder and pancreas are left intact; usually performed to reduce secretion of acid and pepsin by the stomach to cure a peptic ulcer); knowing how to treat gastric acid-related disorders with selective muscarinic receptor antagonists.

(MK) knowing how to study the anatomy of conscious animals by using surgical techniques, such as the Pavlov gastric pouch.

According to Wood (2004, p. 326), Pavlov believed that "chronic studies in surgically prepared conscious animals were most likely to yield new insights into the integrated physiology of organ systems in general and the digestive system in particular." Before Pavlov, experiential physiologists worked mostly with anesthetized animals. Pavlov showed that "sequentially repetitive studies in surgically prepared conscious animals are most likely to advance knowledge basic to humans" (Wood 2004, p. 326). Since Pavlov, it has been a standard methodological principle in physiology that "we must understand the normal functioning of an organ in the alert animal, as well as its anatomy, histology, and cellular biology, to know disease" (Wood 2004, p. 326). Wood (2004, p. 327) also notes that the Pavlov gastric pouch was crucial for "the discovery of the cephalic phase of secretion and its role in the aciticipatory preparation of the upper digestive tract for the ingestion of a meal."

As for practical knowledge, Wood (2004, p. 327) says that "the invention of the nowobsolete selective vagotomy for treatment of peptic and duodenal ulcer disease in humans in the 1930s and the successful pharmacological development of selective muscarinic receptor antagonists as therapy for gastric acid-related disorders emanate from Pavlov's discovery." In addition, "modern knowledge of the action of histamine as a powerful gastric acid secretagogue evolved directly from Pavlov's physiology factory" (Wood 2004, p. 327). Using Pavlov's techniques of surgical preparation of gastric fistulas in dogs, Pavlov's student, L. Popielski, "reported in 1916 that injection of histamine stimulated copious secretion of gastric acid in dogs with surgically prepared gastric fistulas" (Wood 2004, p. 327).

From a naturalistic standpoint, then, one could make the following argument against $(\mathrm{S})$ : 
1. If ( $\mathrm{S}$ ) is true, then scientists would evaluate progress based on criteria that have to do with truth alone. [Assuming that scientists are thoughtful enough to reflect on the aim of their profession and make judgments about whether or not that aim is attained.]

2. It is not the case that scientists evaluate progress based on criteria that have to do with truth alone. [As the aforementioned case studies show.]

3. (Therefore) (S) is (probably) not true.

Like any disconfirmation argument, this argument does not amount to a refutation of (S), even though it is formally valid. Proponents of (S) could always reject the assumption that scientists are cognizant of the aim of science and can make judgments about the attainment of that aim, but then they would have to say why scientists, unlike other professionals, fail to understand the aim of their profession (see footnote 9).

On the other hand, one could make the following argument in support of (E):

1. If $(E)$ is true, then scientists would evaluate progress based on epistemic criteria. [Assuming that scientists are thoughtful enough to reflect on the aim of their profession and make judgments about whether or not that aim is attained.]

2. Scientists evaluate progress based on epistemic criteria. [As the aforementioned case studies show.]

3. (Therefore) (E) is (probably) true.

Like any confirmation argument, this argument does not amount to a demonstration that (E) is true, since it is formally invalid. Again, proponents of (S) could always reject the assumption that scientists are cognizant of the aim of science and can make judgments about the attainment of that aim. But it does seem to provide some evidence in support of (E), since (E) can readily explain why scientists evaluate progress relative to epistemic criteria, whereas (S) does not seem to be able to account for that.

On (S), we get the following picture of science. The scientific enterprise is a truth-aiming enterprise. That is, the aim of scientific inquiry is truth. Scientists are making progress by approaching this goal. More explicitly, they make progress either by accumulating more true beliefs about nature or by getting increasingly closer to the truth. On (S), we are going somewhere worth going, i.e., truth. We are also collecting something worth collecting, i.e., true beliefs (Cf. Godfrey-Smith 2007). What could be more epistemically worthy than truth?

There are several objections to this picture of science. For present purposes, however, I simply wish to see how (S) fares when judged relative to actual scientific practices. As we have seen, scientists assess scientific progress on the basis of criteria that are literally epistemic, i.e., that have to do with knowledge rather than truth alone. More explicitly, scientists consider what was known before a certain discovery, and what is known as a result of that discovery, and if there is an increase in knowledge, then progress has been made. The naturalistic approach requires that a philosophical account of scientific progress be able to account for this scientific practice. 
Truth is indeed epistemically worthy. Since knowledge entails truth, there can be no scientific knowledge without truth. In other words, if $S$ knows that $p$, then $p$ is true (although this does not mean that knowledge can be analyzed in terms of truth plus something else). However, if (S) were true, then, in addition to expecting scientists to talk about the aim of science in terms of truth and evaluate progress relative to the attainment of truth, we would also expect them to value truth alone regardless of methodology. In other words, if the aim of science is truth alone, then we would expect scientists to care about the truth, not about how they get to the truth (Cf. Bird's second argument outlined in Section 1). As we have seen, however, this is not what we find. The case studies discussed above show that, as far as scientists are concerned, justification and methodology are as important as truth. In the case of Landsteiner, the methodological knowhow of antibody purification was deemed as important as the theoretical knowledge of blood groups. And, in the case of Pavlov, the surgical techniques he developed, such as the chronic experiment, were deemed as important as the theoretical knowledge of conditioned reflexes.

From a naturalistic standpoint, then, one could make the following argument against (S):

1. If (S) is true, then scientists would care only about the truth rather than ways of getting to the truth. [Assuming that scientists are thoughtful enough to reflect on the aim of their profession and make judgments about whether or not that aim is attained.]

2. It is not the case that scientists care only about the truth rather than ways of getting to the truth. [As the aforementioned case studies show.]

3. (Therefore) (S) is (probably) not true.

Like any disconfirmation argument, this argument does not amount to a refutation of (S), even though it is formally valid. Proponents of (S) could always reject the assumption that scientists are cognizant of the aim of science and can make judgments about the attainment of that aim, but then they would have to say why scientists, unlike other professionals, fail to understand the aim of their profession (see footnote 9).

On the other hand, one could make the following argument in support of (E):

1. If (E) is true, then scientists would care about ways of getting to the truth, not merely about truth. [Assuming that scientists are thoughtful enough to reflect on the aim of their profession and make judgments about whether or not that aim is attained.]

2. Scientists care about ways of getting to the truth (methodological knowledge). [As the aforementioned case studies show.]

3. (Therefore) (E) is (probably) true.

Like any confirmation argument, this argument does not amount to a demonstration that $(\mathrm{E})$ is true, since it is formally invalid. Again, proponents of $(\mathrm{S})$ could always reject the assumption that scientists are cognizant of the aim of science and can make judgments about the attainment of that aim. But it does seem to provide some evidence in support of $(E)$, since $(E)$ can readily explain why scientists care about ways of getting to the truth, whereas (S) does not seem to be able to account for that.

\section{Varieties of Scientific Knowledge}


It seems to me that Baird and Faust (1990, p. 147) correctly point to the problem of focusing exclusively on theoretical truth in philosophy of science when they write:

Philosophers speak of science in terms of theory and experiment. Yet when they speak of the progress of scientific knowledge, they speak in terms of theory alone. According to most philosophers, experiments are run in order to promote theory; improvements in the ability to experiment are merely instrumental goods that promote the final good of justifying the assertions of a wider and wider domain of sentences. Thus, according to most philosophers, improved theories account for the progress of scientific knowledge. It is our contention that this asymmetry is a mistake. Technicians, engineers and experimenters, in a vast number of instances, are able to make devices work with reliability and subtlety when they can say very little true, or approximately true, about how their devices work. Only blind bias would say that such scientists do not know anything about nature. Their knowledge consists in the ability to do things with nature, not say things about nature (original emphasis). ${ }^{11}$

Using the example of the cyclotron, Baird and Faust show that experimental work in science sometimes proceeds largely without being illuminated or guided by theory because part of the reason for doing experimental work is to provide data that is the material of theoretical work. If this is correct, then (S), given its emphasis on theoretical truth, leaves out important aspects of science (i.e., experimentation, methodology, and practical applications) that scientists seem to take seriously when they evaluate progress.

The case studies discussed above teach us that scientists evaluate scientific discoveries on the basis of the accumulation of knowledge of the following sorts: empirical, theoretical, practical, and methodological. For the most part, philosophers of science have focused on theoretical truth, while underestimating the importance that scientists attribute to empirical knowledge. As these case studies suggest, however, this sort of knowledge plays a role when it comes to evaluating discoveries in science. If a certain scientist is credited with having discovered something that was previously unknown, then that counts as progress, even if the discovery doesn't involve a new elaborate theoretical framework like the ones philosophers of science often focus on (e.g., quantum mechanics).

Another kind of knowledge of interest to scientists that is largely ignored by philosophers of science is practical knowledge (immediate and long-term practical applications). Kitcher, for instance, acknowledges practical progress as a goal of science. But then he sets it aside and goes on to give an account of cognitive progress. The problem, for Kitcher (1993, p. 92), is that "the notion of practical progress proves far more difficult than we might have thought." However, I think that we can begin to make sense of it, in the larger context of scientific progress, from the standpoint of (E). That will allow us to account for the types of knowledge that scientists are interested in. To do so, however, we would have to give up a distinction that is common in

\footnotetext{
${ }^{11}$ Baird and Faust suggest that philosophers of science talk about knowledge, but when they do, it is theoretical knowledge exclusively. It seems to me, however, that Kitcher (2002, p. 385) rightly points out that, within the philosophy of science, "there is little explicit discussion of scientific knowledge."
} 
philosophy, but seems to be of no use when it comes to understanding scientific progress, namely, the distinction between 'knowing that' and 'knowing how to'.

Ryle (1946; 1949) was perhaps the first to distinguish explicitly between 'knowing that p' (propositional knowledge) and 'knowing how to $A$ ' (knowledge of skills). Since then, it seems that philosophers have focused mostly on the former. As we have seen, however, practical and methodological knowledge ('knowing how to') seem to be of equal importance in science when it comes to assessing progress. When Landsteiner's discovery of blood groups was evaluated by his peers and the Nobel Committee, they didn't seem to consider the medical applications of his discovery as less (or more) important than the theoretical knowledge of blood types.

Landsteiner's contributions - theoretical, empirical, practical, and methodological—were judged equally as contributions to scientific knowledge.

Moreover, on closer inspection, it seems that 'knowing how to' may simply be a species of 'knowing that', at least as far as scientific knowledge is concerned, involving propositional knowledge about methods of doing things. For example, suppose that John is getting a blood transfusion and the donor is Jane. Suppose that John has blood type O. In order to perform a safe blood transfusion, we have to know the blood type of Jane. In other words, knowing how to administer safe blood transfusions requires knowing that John has blood type $\mathrm{O}$ and that Jane has blood type $\mathrm{O}$.

When it comes to scientific knowledge, then, it may appear as if 'knowing how to' and 'knowing that' are distinct kinds of knowledge. This appearance, however, may be misleading. According to Wilson (1996, p. 170):

If the thesis that we make knowledge in virtue of our expressing this knowledge verbally were true, it ought to be true quite generally: we would make it true that humans cannot breathe underwater and that iron rusts when exposed to damp air. Yet no one tries to defend this thesis. The reason for the asymmetry is that we can conceive of non-verbal, action-guiding knowledge of the commonplace facts, whereas we cannot easily conceive of an inarticulate knowledge of the scientific facts; these appear to depend in some way not on the world but on our creation of words. But this impression is an illusion. We do not possess two distinct kinds of knowledge, one of which we make. Commonplace knowledge and scientific knowledge belong to the same species, and one aim of scientific praxis is to reduce the perceived distance between them (my emphasis).

The same sort of illusion may be operative in the case of 'knowing that' and 'knowing how to' insofar as scientific knowledge is concerned. Indeed, when we realize that practical knowledge is a form of scientific knowledge, it becomes easier to conceive of action-guiding knowledge of scientific facts, as the aforementioned blood typing example seems to illustrate. This is not to say, of course, that the distinction between 'knowing that' and 'knowing how to' is utterly useless. Rather, the suggestion is simply that it is not useful when it comes to understanding scientific knowledge, and thus scientific progress. Even if 'knowing how to' is not a species of 
'knowing that', ${ }^{12}$ it still seems reasonable to suggest that the former involves cognitive capacities that can be reasonably seen as relevant to cognitive progress in science. In other words, if 'to know' is an achievement verb, then 'knowing how to $A$ ' seems no less an instance of cognitive success than 'knowing that $p$ ' (Adams 1958).

According to Baird and Faust (1990), when most philosophers of science speak of scientific progress, they speak in terms of theory alone, and they neglect other aspects of science, such as experimentation, instrumentation, and methodology. They offer their diagnosis for the source of this mistaken asymmetry (Baird and Faust 1990, p. 148):

Classically, knowledge has been analyzed in terms of true belief. While, perhaps, theories may be conceived as a species of belief, it is difficult to conceive of experiment as a species of belief. Experiment essentially involves the manipulation of bits of the world; belief may help direct the manipulation, but belief cannot take the place of this manipulation. When approached from the classical analysis of knowledge, it is hard to say exactly what is progressing, when speaking of the progress of experimental scientific knowledge (original emphasis).

They urge a conception of scientific progress "broad enough to include the production of new scientific instruments and instrumental techniques" (Baird and Faust 1990, p. 148). They argue that "scientific knowledge consists of, among other things, scientific instruments and instrumental techniques, and not simply some kind of justified true beliefs" (Baird and Faust 1990, p. 148). They also argue that scientific knowledge "consists in the ability to do things with nature, not say things about nature" (Baird and Faust 1990, p. 147). We can accommodate these insights, I suggest, by granting that know-how counts as scientific knowledge. Scientific knowledge, as the case studies discussed above suggest, consists in the cognitive abilities to do things with nature as well as say things about nature. This is how scientists conceive of scientific knowledge. To understand that, however, we need to give up the distinction between 'knowing that' and 'knowing how to', which may be useful in other ways, but not as far as understanding scientific knowledge, and hence scientific progress, is concerned.

To this it might be objected that there are scientific fields that do not seem to have any practical applications, and thus no practical knowledge. It might appear as though fields like cosmology are inherently non-practical. In reply, I should make it clear that I am not saying that all scientific knowledge is know-how. Rather, I am saying that some scientific knowledge is know-how. In addition to know-how, i.e., practical and methodological knowledge, there is also scientific knowledge that is know-that, i.e., empirical and theoretical knowledge.

Moreover, even in cosmology, which might appear to be the typical non-practical scientific field, it is not obvious that there are no concerns for practical applications at all. One example of a potential practical application in cosmology is time travel. This may seem farfetched, but cosmologists and astrophysicists are considering the possibilities of time travel. ${ }^{13}$

\footnotetext{
12 Those who would point to natural language as a way to mark the distinction between 'knowing that' and 'knowing how to' should note that in French the verb savior is used in the sense of 'to know that' as well as 'to know how', whereas the sense of 'being acquainted with' is reserved for the verb connaitre.

${ }^{13}$ See, e.g., Davies (2003) and Gott (2002).
} 
By now, some of the alleged paradoxes of time travel have been shown to be harmless. For example, if we distinguish between "historical time" and "personal time," there is no problem in saying that the time-traveler has gone back in "historical time," not her "personal time." In addition, it is often claimed that if time travel were possible, then one would be able to kill one's parents and thereby prevent one's own birth. In reply, however, it may be argued that, given that the time-traveler was born, no effect she has on the past can change that. In other words, time travel does not mean that the time-traveler has a license to change the past (Horwich 1987). Of course, none of this shows that time travel is physically possible. But this is precisely what cosmologists are trying to find out. One proposal, for example, is that time travel may be physically possible through wormholes in space-time. Gödel (1949) has shown that there are models of space-time that are consistent with general relativity and that allow time travel into the past. ${ }^{14}$ Whether or not time travel will be feasible remains to be seen. For present purposes, it is important to recognize that scientists are concerned with the potential practical applications of their work, even in fields like cosmology, in which it may not appear to be so at first glance.

As for methodological progress (i.e., methods and techniques of learning about nature), according to Devitt (1984, p. 163), "not only are scientists learning more and more about the world, but also [...] they are learning more and more about how to find out about the world."15 Like practical knowledge, methodological knowledge is also a form of know-how, i.e., knowing how to learn about nature. In cosmology, as well, there is a noticeable emphasis on methodological advancements. At the 1995 conference on "Key Problems in Astronomy and Astrophysics," Allan Sandage, a student of Edwin Hubble (1889-1953) at the California Institute of Technology, introduced the term "Practical Cosmology." It was an attempt to respond to the charge that cosmology was an "immature" scientific field with plenty of fascinating ideas but no substantial data to confirm them. To address this charge, Sandage and others thought that they must devote more attention to the methodological aspects of their work, specifically the ways in which astronomical observations are conducted and the ways in which data are gathered and analyzed. This was Sandage's vision of practical cosmology, which was discussed recently in the international conference "Problems of Practical Cosmology" (Baryshev 2008):

The advancement of cosmology is determined by the growth of observational data and $[\ldots]$ by the development of fundamental physical theories. Practical cosmology is the science which makes a link between observation and theory. The major goal of practical cosmology is to develop strategies for uncovering and attacking cosmological problems. Even with the wonderful advanced observational methods available, successful cosmological tests require that we know how to detect and handle different severe selection effects, which may be hidden both in data and, even seemingly secure, methods of data analysis (my emphasis). ${ }^{16}$

Some of these strategies and methods include the "classical cosmological tests," red-shift surveys, measurements of anisotropies of the cosmic background radiation by balloon and satellite (e.g., the Wilkinson Microwave Anisotropy Probe) experiments, and fractal techniques.

\footnotetext{
${ }^{14}$ See also Pfarr (1981).

${ }^{15}$ See also Kitcher (1993), p. 140.

${ }^{16}$ Available at <http://ppc08.astro.spbu.ru/index.html>.
} 
By being able to account for both cognitive and practical progress, (E) exhibits theoretical virtues, such as simplicity and unification. It is a simple view of progress because it accounts for the varieties of progress mentioned above by means of one concept. A revised concept of scientific knowledge, which includes not only propositional knowledge but also know-how, would allow us to account for these varieties of progress in a unified manner, incorporating both practical and cognitive progress. In that respect, (E) preserves what is useful and illuminating about (S), namely, that truth is necessary for progress, and incorporates it into a comprehensive view of scientific progress.

\section{Conclusion}

According to Bird (2007, p. 65), "Given that science is an epistemic activity it seems almost tautologous to suggest that its success and so progress should be measured by epistemic standards." On (E), knowledge, rather than truth alone, is the concept we need in order to understand scientific progress. (E) says that a scientific episode constitutes scientific progress precisely when it shows the accumulation of scientific knowledge. Bird shows that (E) and (S) diverge insofar as taking beliefs with insufficient epistemic support to count as knowledge is concerned.

As far as accounting for scientific progress is concerned, (E) seems more promising than (S) insofar as it seems to be consistent with actual scientific practices. On (S), the scientific enterprise is a truth-aiming enterprise, and so we would expect to find that scientists talk about the aim of science in terms of truth, that scientists evaluate progress in science relative to criteria that have to do with truth alone, and that scientists care about truth alone rather than ways of getting to the truth. But this is not what we find. In fact, scientists talk about the aim of science in terms of knowledge, they evaluate progress relative to epistemic criteria, and they seem to value methodology as much as they value truth. These findings are consistent with (E), since according to $(\mathrm{E})$, science is a knowledge-seeking enterprise. Scientific progress consists in the accumulation of scientific knowledge. (E) takes truth to be necessary (since knowledge is factive), but not sufficient, for scientific progress. In addition to truth, justification and reliable methods are also necessary for scientific progress. ${ }^{17}$ In that respect, unlike (S), (E) can account for actual scientific practices. Scientists not only conceive of the aims of science in epistemic terms but also assess scientific progress on the basis of epistemic criteria.

I think that Bird is right about knowledge being the concept we need in order to understand scientific progress. But I also think that (E) needs to be revised in light of the aforementioned considerations. I propose to take seriously the lessons of the case studies discussed above. These are that (a) scientists take scientific knowledge to be the aim of scientific inquiry; (b) scientists make judgments about scientific progress based on the accumulation of scientific knowledge; (c) scientists take scientific knowledge to include not only theoretical knowledge but also empirical, practical, and methodological knowledge. Each contribution to scientific knowledge in terms of one of these types of knowledge counts as progress. Science

\footnotetext{
${ }^{17}$ By necessary and sufficient conditions here, I do not mean "individually necessary and jointly sufficient" as in conceptual analysis, but rather collectively sufficient for scientific progress, or better yet, constitutive criteria for progress.
} 
advances owing to not only the grand scale theoretical frameworks of theoreticians but also the work of experimenters and data collectors, lab technicians, field workers, and the like.

If this is correct, then we should revise (E) to include not only theoretical knowledge but also these other types of knowledge. We can do so, I suggest, if we grant that 'knowing how' (practical and methodological knowledge) is a species of 'knowing that' (theoretical and empirical knowledge). Even if it isn't, it still seems reasonable to take advances in practical and methodological knowledge as instances of cognitive success, and hence cognitive progress, in science. Granted that practical and methodological knowledge both count as scientific knowledge, and hence that their accumulation counts as scientific progress, the revised epistemic account of scientific progress is the view that scientific progress is constituted by the accumulation of scientific knowledge. A scientific episode is progressive when it shows the accumulation of scientific knowledge, where scientific knowledge consists of each the following: empirical, theoretical, practical, and methodological knowledge. Each of these counts as scientific knowledge; the accumulation of each advances science.

\section{Acknowledgments}

A version of this paper was presented at the Third Biennial Conference of the Society for Philosophy of Science in Practice in University of Exeter, UK in June 2011. I would like to thank the audience and members of the organization committee for their helpful feedback. I am grateful to the PSC-CUNY for the generous financial aid and travel funds. I am also indebted to Alberto Cordero, Catherine Wilson, and Joseph Dauben for their comments on earlier drafts of this paper.

\section{References}

Adams, E. M. (1958). On Knowing that. The Philosophical Quarterly, 8, 300-306.

Baird, D., \& Faust, T. (1990). Scientific Instruments, Scientific Progress and the Cyclotron. British Journal for the Philosophy for Science, 41, 147-175.

Baryshev, Y. (2008). Practical Cosmology and Cosmological Physics. Paper presented at the Problems of Practical Cosmology, Saint-Petersburg.

Bird, A. (2000). Thomas Kuhn. Princeton, NJ: Princeton University Press.

Bird, A. (2007). What Is Scientific Progress? Nous, 41, 64-89.

Bird, A. (2008). Scientific Progress as Accumulation of Knowledge: A Reply to Rowbottom. Studies in the History and Philosophy of Science, 39, 279-281.

Chang, H. (2007). Scientific Progress: Beyond Foundationalism and Coherentism. Royal Institute of Philosophy Supplement, 82, 1-20.

Davies, P. (2003). How to Build a Time Machine. New York: Penguin Books.

Devitt, M. (1997). Realism and Truth (2nd ed.). Princeton, N.J.: Princeton University Press.

Gödel, K. (1949). An example of a new type of cosmological solutions of Einstein's field equations of gravitation. Review of Modern Physics, 21, 447-450.

Godfrey-Smith, P. (2007). Progress and Procedures in Scientific Epistemology. Paper presented at the 2007 Reichenbach Lecture at UCLA. Retrieved from http://philoscience.unibe.ch/documents/TexteFS09/Godfrey-Smith2007.pdf. 
Gott, J. R. (2002). Time Travel in Einstein's Universe: The Physical Possibilities of Travel through Time. New York: Houghton Mifflin Books.

Hacking, I. (Ed.). (1981). Scientific Revolutions. New York: Oxford University Press.

Hacking, I. (1983). Representing and Intervening: Introductory Topics in the Philosophy of Natural Science. New York: Cambridge University Press.

Hedrén, G. (1930). Presentation Speech. The Nobel Prize in Physiology or Medicine. Nobel Lectures, from http://nobelprize.org/nobel_prizes/medicine/laureates/1930/press.html.

Horwich, P. (1987). Asymmetries in Time. Cambridge, MA: Cambridge University Press.

Kitcher, P. (1983). Abusing Science: The Case Against Creationism. Cambridge, MA: The MIT Press.

Kitcher, P. (1993). The Advancement of Science: Science without Legend, Objectivity without Illusions. New York: Oxford University Press.

Kitcher, P. (2002). Scientific Knowledge. In P. K. Moser (Ed.), The Oxford Handbook of Epistemology (pp. 385-407). New York: Oxford University Press.

Kuhn, T. S. (1959). The Essential Tension: Tradition and Innovation in Scientific Research. In C. Taylor (Ed.), The Third University of Utah Research Conference on the Identification of Scientific Talent (pp. 162-174). Salt Lake City: University of Utah Press.

Kuhn, T. S. (1970). Logic of Discovery or Psychology of Research? In I. Lakatos \& A. Musgrave (Eds.), Criticism and the Growth of Knowledge (pp. 1-24). New York: Cambridge University Press.

Kuhn, T. S. (1977). The Essential Tension: Selected Studies in Scientific Tradition and Change. Chicago: University of Chicago Press.

Kuhn, T. S. (1992). The Trouble with the Historical Philosophy of Science. Cambridge, MA: An Occasional Publication of the Department of the History of Science Harvard University.

Kuhn, T. S. (1996). The Structure of Scientific Revolutions (3 ed.). Chicago: The University of Chicago Press.

Landsteiner, K. (1930). Nobel Lecture: On Individual Differences in Human Blood. Nobel Lectures, from http://nobelprize.org/nobel_prizes/medicine/laureates/1930/landsteinerlecture.pdf.

Landsteiner, K., \& Miller, P. C. (1925). Serological Studies in the Blood of the Primates: II. The Blood Groups in Anthropoid Apes. The Journal of Experimental Medicine, 42, 853-862.

Lakatos, I. (1970). History of Science and its Rational Reconstructions. PSA: Proceedings of the Biennial Meeting of the Philosophy of Science Association, 1970, 91-136.

Laudan, L. (1977). Progress and its Problems: Toward a Theory of Scientific Growth. Berkeley: University of California Press.

Laudan, L. (1978). The Philosophy of Progress... PSA: Proceedings of the Biennial Meeting of the Philosophy of Science Association, 2: Symposia and Invited Papers, 530-547.

Laudan, L. (1981). A Problem-Solving Approach to Scientific Progress. In I. Hacking (Ed.), Scientific Revolutions (pp. 144-155). New York: Oxford University Press.

Laudan, L. (1984). Science and Values: The Aims of Science and their Role in Scientific Debate. Berkeley: University of California Press.

Leplin, J. (1997). A Novel Defense of Scientific Realism. New York: Oxford University Press. 
Mörner, K. A. H. (1904). Presentation Speech. The Nobel Prize in Physiology or Medicine. Nobel Lectures, from http://nobelprize.org/nobel_prizes/medicine/laureates/1904/press.html.

Niiniluoto, I. (1984). Is Science Progressive? Boston, MA: Kluwer Academic Publishers. Niiniluoto, I. (1987). Truthlikeness. Boston, MA: Kluwer Academic Publishers.

Pavlov, I. (1904). Nobel Lecture: Physiology of Digestion. Nobel Lectures, from http://nobelprize.org/nobel_prizes/medicine/laureates/1904/pavlov-lecture.html.

Pfarr, J. (1981). Time Travel in Gödel's Space. General Relativity and Gravitation, 13, 10731091.

Popper, K. R. (1968). Conjectures and Refutations: The Growth of Scientific Knowledge. New York: Harper \& Row.

Popper, K. R. (1979). Objective Knowledge: An Evolutionary Approach (Revised 1979 ed.). Oxford: Clarendon Press.

Popper, K. R., \& Bartley, W. W. (1982). Realism and the Aim of Science. Totowa, N.J.: Rowman and Littlefield.

Quine, W. V. O. (1953). Two Dogmas of Empiricism From A Logical Point of View. Cambridge, MA: Harvard University Press.

Quine, W. V. O. (1969). Epistemology Naturalized Ontological Relativity and Other Essays (pp. 69-90). New York: Columbia University Press.

Rowbottom, D. (2008). N-Rays and the Semantic View of Scientific Progress. Studies in the History and Philosophy of Science, 39, 277-278.

Rowbottom, D. (2010). What Scientific Progress Is Not: Against Bird's Epistemic View. International Studies in the Philosophy of Science, 24, 241-255.

Rutherford, E. (1947). The Scientist. In R. B. Heywood (Ed.), The Works of the Mind. Chicago: University of Chicago Press.

Ryle, G. (1946). Knowing How and Knowing That. Proceedings of the Aristotelian Society, XLVI.

Ryle, G. (1949). The Concept of Mind. New York: Barnes \& Noble.

Sarton, G. (1927). Introduction to the History of Science. Baltimore: Carnegie Institution of Washington.

Spedding, J., Ellis, R. L., \& Heath, D. D. (Eds.). (1857-74). The Works of Francis Bacon. London: Longman.

Williamson, T. (1997). Knowledge as Evidence. Mind, 106, 717-741.

Williamson, T. (2000). Knowledge and Its Limits. New York: Oxford University Press.

Wilson, C. (1996). Instruments and Ideologies: The Social Construction of Knowledge and Its Critics. American Philosophical Quarterly, 33, 167-181.

Wilson, E. O. (1999). Consilience: The Unity of Knowledge. New York: Random House.

Wood, D. J. (2004). The First Nobel Prize for Integrated Systems Physiology: Ivan Petrovich Pavlov, 1904. Physiology, 19, 326-330.

Zuckerman, H. (1996). Scientific Elite: Nobel Laureates in the United States (2 ed.). New Brunswick, NJ: Transaction Publishers. 